\title{
Actualidad
}

\section{NUEVOS CONCEPTOS SOBRE LA ETIOPATOGENIA Y TRATAMIENTO DEI. ESTRABISMO}

\author{
Por el Dr. AlFRedo villaseca E.
}

Visión binocular.

Una de las características distintivas del hombre y de los primates es el hecho de que los ojos están dirigidos directamento adelante, de tal modo que los ejes visuales son prácticamente paralelos. El objeto de este paralelismo es la creación de un campo máximo de vísión binocular.

La gran ventaja de la visión binocular es la exacta percepción de la profundidad (visión estereoscópica), la que permite una adecuada localización en el espacio de objetos más o menos distantes.

En los demás animales los ojos están colocados más lateralmente, permitiendo un campo visual monocular más grande de cada lado, a cambio de un reducido campo de visión binocular hacia adelante.

En la fig. 1 se representa un diagrama de las vías visuales humanas. Los objetos siluados a la derecha del punto de fijación forman sus imágenes en las hemiretinas izquierdas, las que son trasmitidas al lóbulo occipital izquierdo, debido a la parcial decusación do las fibras ópticas a nivel del quiasma. Tales imágenes son proyectadas mentalmente a la derecha. Lo inverso sucede para los objetos situados a la izquierda del punto de fijación.

Aquellos pares de puntos retinalos que cuando estimulados dan la impresión de un objeto único, se llaman pantos correspondientes. Las dos máculas son puntos correspondientes, como también todos los puntos retinales equidistantes de las máculas hacia arriba, abajo, durecha o izquierda.

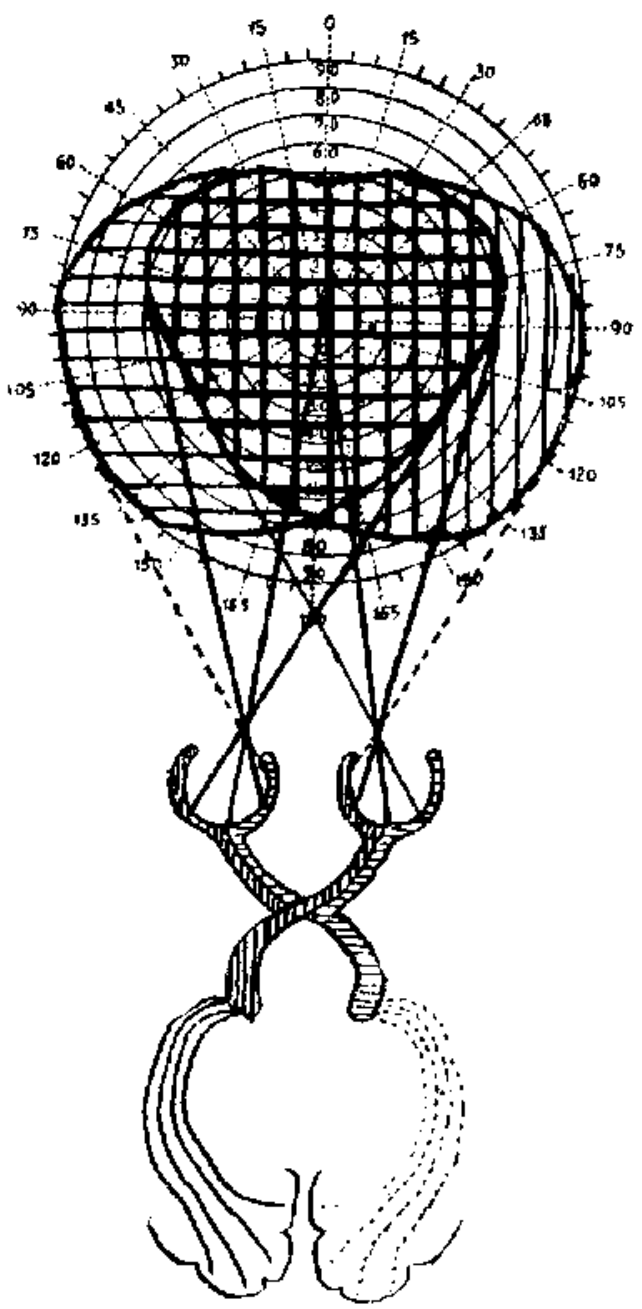

Fig. 1.

En la figura se ve que el campo de visión binocular es extenso, abarcando un área casi circular do unos $100^{\circ}$ de 
diámetro. De cada lado hay un pequeño campo monocular en forma de creciente de 30 a $40^{\circ}$ de ancho.

Los movimientos oculares están regidos por 12 músculos (6 para cada ojo), los cuales deben contraerse y relajarse sinérgicamente para provocar igual desplazamiento en ambos ojos.

El objeto del movimiento sincrónico de ambos ojos es permitir la formación de las imágenes de cada objeto del mundo exterior en puntos correspondientes de ambas retinas.

Las dos imágenes presentadas al cerebro por zonas retinales correspondien-

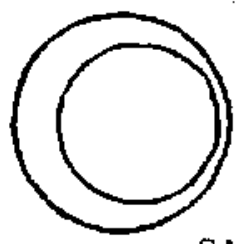

F L . 2.-

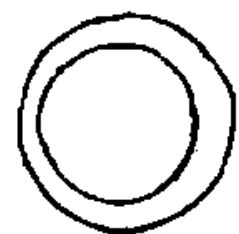
tes de cada ojo, son fundidas por un
proceso perceptual superior en una sola imagen con el atributo de la profunddad, o imagen estereoscópica.

La imagen única tridimensional no es el simple producto de una superposición de dos imágenes unioculares ligeramente diferentes, sino de una elaboración mental compleja.

Si en el estereoscopio se presentan, por ejemplo, las siguientes imágenes a cada ojo (fig. 2), no se obtiene una imagen superpuesta, como sería la de la figura 3 , sino una imagen como la de la figura 4 , percibiéndose el círculo menor en un plano muy anterior con respecto al círculo mayor.

Reflejos octulares bases de la visión binocular.

El desarrollo del mecanismo binocalat en el niño es materia de importancia. Correspondiendo a su tardía adquisición en la filogenia, este mecanismo es adquirido post-natalmente.

El reflejo postural (rotación de los ojos sobre sus ejes antero-posteriores al inclinar la cabeza sobre uno a otro hombro), de origen vestibular, es innato, completándose automáticamente antes del nacimiento, y funcionando independientemente de estímulos visuales (aun en caso de cegueta congénita). Es, pues, un reflejo típicamente incondicionado.

El reflejo de fijación monocular está también presente al nacer, pero sólo débilmente desarrollado. Si en una pieza oscura se deja caer luz en el ojo del niño de pocas horas, el ojo se dirige inmediatamente hacia la luz. Esta fijación es, sin embargo, sólo momentánoa. EI recién nacido no puede mantener la fijación de una luz fija, pero por brusco encendido de la luz, el reflejo
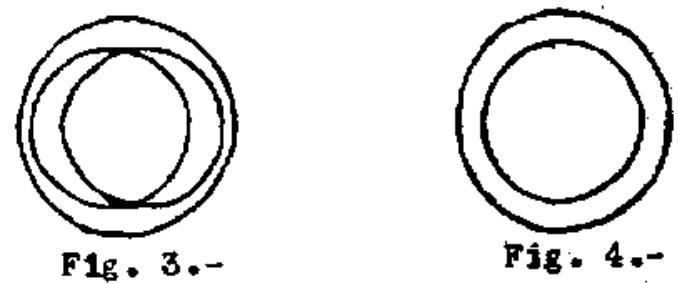

de fijación monocular puede ser repetidamente obtenido.

$A$ las 2 ó 3 semanas de edad la mayoría de los niños logra mantener la fijación de la luz durante algunos segundos con uno u otro ojo, pero no con ambos simultáneamente.

A las 5 ó 6 semanas de edad, el reflejo de fijación conjugada comienza a establecerse y ambos ojos son capaces de seguir a una luz durante algunos sogundos. A ratos, sin embargo, un ojo girará un poco más adentro o más afuera de lo que le corresponde.

A Ios 3 meses de edad los ojos seguirán juntos a un objeto pequeño y se hace aparente la transición de una fijación refleja a una fijación consciente de la mirada. A los 4 meses la mano tratará de agarrar el objeto $y$ ya se hai desarrollado movimientos laterales rápidos de los ojos; pero sólo a los 6 meses de edad los movimientos conjagados son perfectamente exactos.

El reflejo de convergencia se desarrolla paralelamente, aunque algo más tarde que el reflejo de fijación conju* gada. A los 6 meses está también desarrollado. 
El reflejo correctivo de fusión comienza a desarrollarse a los 5 a $6 \mathrm{me}-$ ses, pudiendo observarse a esta edad que si se coloca rápidamente un prisma de $8^{\circ}$ delante de un ojo del niño, con vértice hacia la nariz, a veces el ojo rota hacia adentro y otras veces sigue derecho sin rotar. Al año este reflejo está siempre desarrollado, observándose con constancia el movimiento compensador de rotación al intercalar el prisma.

El ojo del niño tiene, además, otras diferencias de tipo anatómico y funcional con respecto al ojo adulto.

a) La mácula está poco desarrollada y la agudeza visual al nacer sólo se estima en 6/1,000, subiendo gradualmente hasta llegar a $6 / 36$ al cabo de un año, a $6 / 12$ a $\operatorname{los} 2$ años, $6 / 9$ a los 3 años, $6 / 7$ a los 4 años y a $6 / 6$ sólo a los 5 años de edad.

b) El músculo ciliar está escasamente desarrollado en el recién nacido y sólo alcanza su desarrollo completo a los 2 ó 3 años de edad. La acomodación y consiguiente nitidez en la visión de los abjetos cercanos sólo se alcanza, pues, tardíamente.

El reflejo de la acomodación y el reflejo de la convergencia, por el uso simultáneo cada vez que se enfoca un objeto cercano, se van asociando sinérgica mente en el importante reflejo condicionado de la acomodación-convergencia, cuya fina integración resulta en la elaboración de una imagen biretinal nitida $\mathrm{y}$ única para todas las distancias.

En resumen, el aparato visual está imperfectamente desarrollado al nacer. Por la continuación post-natal de su diferenciación normal, y sobre todo por sa uso continuado, que va creando ana serie sucesiva (y cada vez más compleja) de reflejos condicionados, se establece progresivamente la visión binocular normal.

El reforzamiento continuo de estos reflejos condicionados durante los primeros años de vida, en que el cerebro está en un estado plástico, los va consolidando hasta que altededor de los 5 años de edad adquieren un automatis- mo y fijeza comparables a los de un reflejo incondicionado.

El hecho fundamental es que si estos reflejos normales no son desarrollados. y hasta cierto punto fijados, mientras el sistema nervioso es todavía plástico (más o menos hasta los 7 años do edad), no serán nunca desarrollados.

Si durante este período hay un desarrollo de reflejos condicionados patológicos (como veremos más adelante es Io que sucede en el niño estrábico que no es tratado precozmente), ellos tenderán a adquirir la misma fijeza que un reflejo normal y no serán posteriormente susceptibles de ser modificados. Sucede algo similar en el niño con labio leporino complicado, que es tratado tardiamente, cuando ya se ba desarrollado y fijado el reflejo condicionado de la palabra hablada, en el que a pesar de la curación quirúrgica del defecto anatómico del paladar subsiste el lenguaje con fuerte acento nasal.

\section{Etiopatogenia del estrabismo.}

De lo dicho anteriormente fluye naturalmente el enunciado de Chabasse (1939), que dice que el estrabismo "es ana perversión del desarrollo de los reflejos binoculares".

Cualquier obstáculo al normal desarrollo de los reflejos binoculares provocará la disociación ocular manifiesta que llamamos estrabismo. Este obstáculo puede estar situado en cualquier punto del arco reflejo, distinguiéndase según esto: obstáculos sensoriales, motores y centrales.

1) Obstáculos sensoriales: a) cubrimiento prolongado de un ojo en un niño pequeño; b) cristal incorrecto frente a un ojo; c) anisometropía (vicio de refracción monocular o preferentemento monocular) ; d) opacidades unilaterales de la córnea o cristalino; e) lesiones maculares o del nervio óptico.

2) Obstáculos motores: a) Funci-onales: Hipermetropía. Se recordará que en este vicio de refracción el ojo es muy corto, por lo que las imágenes se forman 
por detrás de la retina cuando no entra en juego la acomodación. Un niño hipermétrope se encuentra ante 3 alternativas: $1^{\circ}$ ) Aumentar la acomodación hasta obtener una imagen nítida, con aumento sinérgico de la convergencia $y$ producción de un estrabismo convergente; $2^{\circ}$ ) Acomociar en forma insufi-

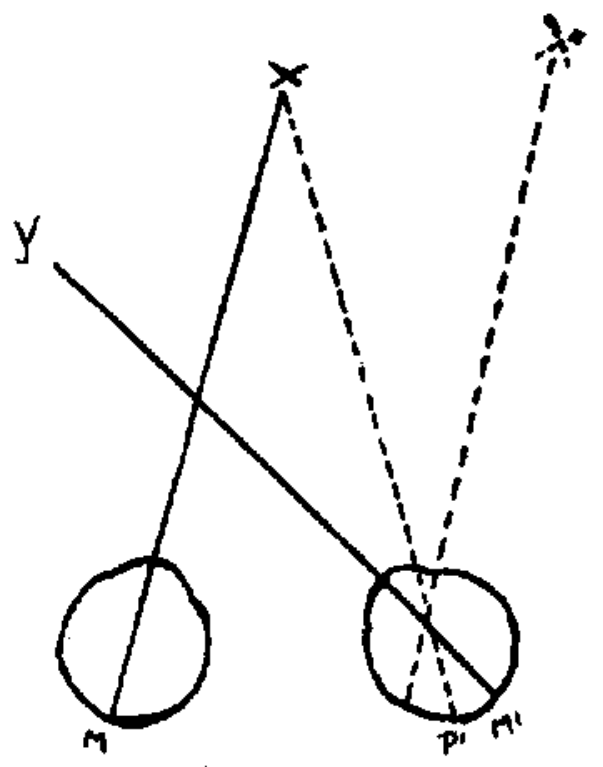

EHg. 5.

ciente, a costa de una visión borrosa, en tal forma que la convergencia se mantenga normal; $3^{\circ}$ ) Alterar la telación entre el reflejo de acomodación $Y$ el reflejo de convergencia, de modo que a una mayor acomodación (que permita una visión nítida), corresponda una menor convergencia (que permita una adecuada fijación binocular). b) Parálisis musculares: congénitas (traumatismo obstétrico, aplasias de los núcleos motores) 0 adquiridas (encefalitis, hemorragias, traumatismos (raneanos, etc.).

3) Obstáculos centrales: a) En casos de idiocía acentuada no se desarrollan Ios reflejos binoculares; b) en el período én que los reflejos están en vías de desarroIlo (hasta los 5 a 7 años de edad), las enfermedades infecciosas y febriles de la infancia pueden perturbar el equilibrio nervioso, transformando una alteración latente compensada del balance muscu- lar (como la que se encuentra en un niño con hipermetropía moderada en proceso de reajuste de sus reflejos de acomodación y convergencia) en un desequilibrio manifiesto o estrabismo, c) Existen estrabismos de origen psicológico: celos por la llegada de un hermanito, miedo, etc.

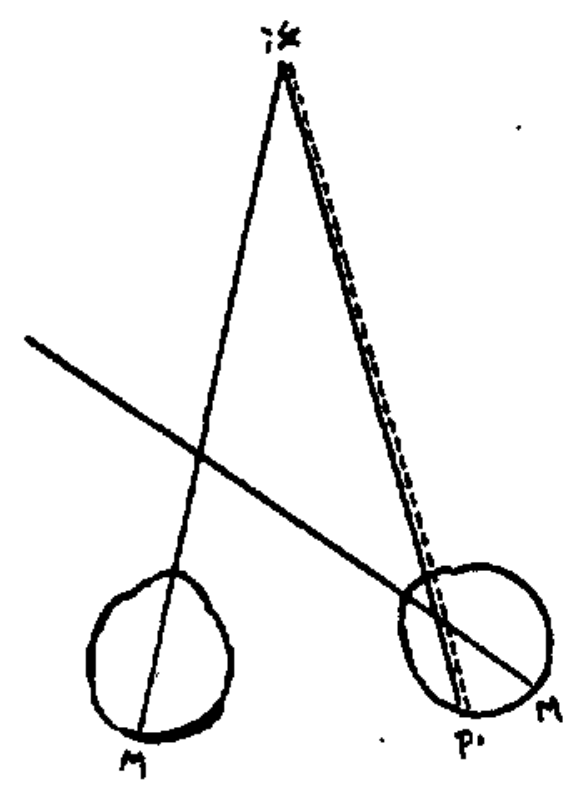

Fing. 6.

En resumen, pues, el estrabismo es un "sindrome" que puede ser producido por múltiples y variadas causas, las que sólo tienen de común el hecho de constituir obstáculos para el normal desarrollo de las reflejos binoculares. Estos obstáculos pueden ser de naturaleza y localización anatómica diversa. Ellos deben naturalmente manifestarse en aquel período, en que se están moldeando en el sistema nervioso plástico del niño los reflejos condicionados de la visión binocular.

\section{Sintomatologia,}

Al producirse un estrabismo existen sólo 3 posibilidades visuales: 1) Visión doble (diplopia) al formarse las imágenes en cada ojo on puntos no correspondientes de las retinas (fig. 5). El obje- 
to $\mathrm{X}$ forma su imagen en la mácula del O. I. y en un punto nasal Pl del O. D. siendo esta última proyectada mentalmente bacia la derecha (XI).

2) Supresión de las imágenes del ojo desviado: El cerebro suprime la Imagen XI para evitar la diplopia y la del objeto $Y$ que se superpone sobre el objeto $\mathrm{X}$ (por caer sobre la mácula del $\mathrm{O}$. $\mathrm{D}$. $\mathrm{Y}$, por lo tanto, ser también proyectada mentalmente hacia adelante).

3) Creación de una correspondencia retiniana anómala (fig. 6). Se produce un reajuste patológico, por el cual el punto PI es proyectado mentalmente hacia adelante en vez de a la derecha, pasando, pues, a ser punto correspondiente con la mácula del otro ojo. Este nuevo tipo de asociación binocular anómala no alcanza una utilidad práctica para el niño estrábico (salvo la de evitar la diplopia), puesto que la imagen del ojo desviado no es una imagen clata por caer en un área periférica de la retina, donde la agudeza visual es pobre.

La supresión y la correspondencia retiniana anómala son reflejos condicionados patológicos que se desarrollan por el uso continuado de los ojos en posición incorrecta.

En los estrabismos unioculares ol reflejo de la supresión, al funcionar permanentemente, llega con el tiempo a hacerse fijo e incondicionado, constituyendo el conocido fenómeno de la ambliopía del ojo estrábico. La cegueta se establece gradualmente por la inhibición activa de la visión ya desarrollada en el niño, pero que aun no había alcanzado una fijeza incondicionada.

En 400 casos consecutivos de estrabismo M. Pugh encontró el siguiente porcentaje:

Supresión

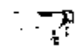

Diplopla aceptada $\ldots \begin{array}{llllll}. & \ldots & \ldots & \ldots & \ldots & 2.8 \%\end{array}$

Correspondencia retinlana anómala $42 \%$

Falsa mácula .. . . . . . . . . . . . . . 2 2 \%

En casi todos los estrabismos (después de un estado inicial de diplopia) se desarrolla, pues, el reflejo condicionado patológico de la supresión (con su secuela la ambliopía) o de la correspondencia retiniana anómala.

\section{Examen al sinoptóforo.}

Este aparato es una evolución del estereoscopio. Tiene una base pesada de fierro, en la cual se articulan dos ejes verticales, que terminan por su extremo superior en dos tubos acodados. Estos tubos pueden girar sobre sus ejes. en la base de los cuales hay una escala graduada, adaptándose a estrabismos convergentes o divergentes.

En el extremo ocular de estos tubos hay un lente +6.5 D. que tiene por objeto relajar la acomodación. En el extremo distal hay una ranura, en la cual se introducen diversos diapositiv'os.

En general éstos se dividen en 3 tipos:

I. Diapositivos de percepción simultánea.

Consisten en pares de figuras distintas que se colocan frente a cada ojo, como: un león y un a jaula, un automóvil y un garage, una mariposa y una red, un soldado y una caseta, etc.

2. Diapositivos para fusión.

Consisten en pares do figuras similares, con una parte diferente que sirve de control. Por ejemplo, se coloca la figura de un gato sin cabeza frente a un ojo y del mismo gato con cabeza, pero sin cola frente al otro ojo. Cuando las imágenes de ambos ojos son fusionadas en el cerebro se percibe un solo gato con cola y cabeza. Así hay múltiples ingeniosas figuras, cuya unión constituye un entretenido juego para el niño (figuras de Mickey Mouse, casas, etc.).

3. Diapositivos estereoscópicos.

Estas figuras están diseñadas de modo de producir el efecto de paralaje binocular, y de esta manera un efecto estercoscópico. Una figura muy usada es la del balde en que el niño debe indicar si está mirando dentro del balde o si lo ve pot fuera como un balde inver- 
tido. En otra figura deberá indicar si el columpio lo ve balancearse hacia él o hacia el examinador.

Se comienza colocando los diapositivos de percepción simultánea como el león y la jaula. des:

Pueden presentarse tres posibilida-

a) El niño coloca el león dentro de la jaula en el ángulo objetivo del estrabismo, en cuyo caso hay percepción maculat simultánea con correspondencia retiniana normal.

b) Al acercarse el león a la jaula desaparece la imagen del león o de la jaula, en cuyo caso existe el fenómeno o reflejo condicionado patológico de la supresión (fig. 5).

c) El niño logra colocar el león dentro de la jaula, pero a un ángulo distinto del ángulo objetivo del estrabismo, en cuyo caso hay una correspordencia retiniana anómala (fig. 6 ).

En caso de producitse la primera situación, se seguirá el estudio con diapositivos de fusión y estereoscópicos.

Sólo si el paciente logra pasar satisfactoriamente estas tres etapas, se puede decir que se ha desarrollado la v1sión binocular normal.

En resumen, el sinoptóforo es un aparato de gran utilidad para el estudio de los casos de estrabismo:

1) Permite una exacta medición del estrabismo en forma objetiva, en su componente horizontal y vertical.

2) Permite detectar pequeñas inconcomitancias, revelando antiguas paresias musculares casuales.

3) Permite el estudio y medición de los reflejos condicionados patológicos de la supresión y correspondencia retiniana anómala.

4) Permite estudiar el grado de desarrollo de la visión binocular normal (percepción simultánea, fusión, visión estereoscópica).
Tratamiento.

La finalidad del tratamiento debe ser la cura funcional del estrabismo, o sea, la restauración de la visión binocular normal.

La posibilidad de curación en este sentido dependo primariamente de la precocidad con que es tratado el caso.

Duke Elder ${ }^{3}$ comienza su capítulo sobre tratamiento del estrabismo cor las siguientes palabras:

"En el tratamiento de los estrabismos originados on la niñez, el factor más importante es el Tiempo y la consideración mayor la Urgencia. Un gran número de estrabismos puede ser prevenido si la causa es removida o neutralizada a tiempo; un gran número puede ser curado, en el sentido de obtener una restauración completa de la función normal, siempre que el tratamiento sea aplicado sin tardanza: para un caso descuidado ningún tratamiento es realmente curativo. Jamás se experimenta la menor duda para tratar la ceguera inminente por glaucoma como un caso de urgencia, o para usar todos los recursos de la medicina para prevenir la pérdida de la visión central en un caso de coro1ditis progresiva; pero la ceguera de la ambliopía por desarrollo de un escotoma central en un niño estrábico es a menudo despedida con vana esperanza de que el paciente "curará al crecer" o de que la deformidad (la función es de paso descuidada) se rectificará eventualmente por sí sola. Mientras esta tradición exista, mucha de la terapéutica del estrabismo quedará confinada a tentativas groseras y frecuentemente ineficaces para mitigar secuelas totalmente innecesarias de la condición original, y el arte de la oftalmología quedará relegado al mantenimiento de una fachada cosmética".

Los resultados de la antigua escuela, que aconsejaba esperar hasta que el niño crecierg. se ponen de manifiesto en e] siguiente cuadro de M. Pugh. 
214 casos consecutivos operados tardiamente sin tratamiento ortóptico.

Ejes paratelos .

$7,94 \%$

Desviación residual de $10^{\circ}$ a menos 51,4 \%

Desviación residual de 10 a $20^{\circ} \ldots \ldots 31,31 \%$

Desviación residual sobre $20^{\circ} \ldots \ldots \ldots .9,35 \%$

\section{Estado de la visión binocnlar.}

Cornesp. retiniana anómala . 63,19\% Eupresión . . . . . . . . . . . . 14,72\% $78 \%$

Percepción macular simultánea $10,43 \%^{-} \mathrm{j}^{-}$ Fusión . . . . . . . . . . . . .

Alguin graido de visión estereoscónica . . . . . $\ldots \ldots \ldots \ldots . . .1,84 \%$ $12 \%$

En el $78 \%$ persistían inmodificados los reflejos patológicos de la supresión y correspondencia retiniana anómala. Sólo un $12 \%$ tenían cierto grado de fusión y un $1,84 \%$ algún grado de visión estereoscópica.

Las etapas generales del tratamiento son las siguientes:

\section{Eimminación de la caụsa.}

Si existe una diferencia en Ia refracción de cada ajo (anisometropia) que impide la fusión de dos imágenes retinales de diferente nitidez, es indispensable corregir sin tardanza el defecto por medio del uso de los cristales correctores. Esta corrección óptica debe aplicarse inmediatamente, cualquiera sea la edad del niño.

Lo mismo si existe un excesa de convergencia asociado a una acomodación excesiva por hipermetropia, el niño debe usar la corrección óptica portinente inmediatamente.

En los niños muy pequeños se usan monturas especiales con piezas laterales rectas terminadas en una hendidura, por donde se introducen cintas que son amarradas detrás de la cabeza.
En los casos de estrabismo de causa psicológica, ningún tratamiento (óptico, ortóptico o quirúrgico) será eficaz mientras no se elimine el factor causal.

\section{Tratamiento de la ambliopía. Oclusión del ojo fijador.}

No bay que olvidar que la ambliopía de extinción se adquiere por un proceso activo de inhibición, originado en la mácula del ojo fijador. De ello se desprende que durante todo el tiempo en que ambos ojos permanecen abiertos, se está reforzando este reflejo inhibitorio.

No se saca nada, pues, con ocluir el ojo fijador por algunas horas del día solamente, sino que la oclusión debe ser total y permanente.

La cantidad de visión recuperable por oclusión varía con la edad en que comenzó el estrabismo (o sea la agudeza visual que se había desarrollado antes que la inhibición se hiciera efectiva) y con el tiempo durante el cual se mantuvo operante esta inhibición. De aquí que la oclusión del ojo fijador traiga una rápida mejoría de la ambliopía en los niños pequeños, y en cambio, sobre los 7 u 8 años de edad la mejoría sea muy lenta y a menudo incompleta.

Si persiste el estrabismo una vez alcanzada una visión igual en ambos ojos, deberá continuarse con la oclusión altetnada de cada ojo hasta que se haya corregido la desviación de los cjes oculares por medio de una operación, para evitar el desarrollo de reflejos patológicos, como la supresión o correspondencia retiniana anómala.

A este respecto ninguna edad es demasiado temprana para comenzar un tratamiento. En un estrabismo congénito, por ejemplo, mientras se espera para tomar otras medidas, debe ocluirse alternadamente cada ojo para evitar el desarrollo de reflejos pervertidos, los que a esta edad se desarrollan y fijan con extraordinaria rapidez. 
III. Tratamiento de la supresión $y$ de la correspondencia retiniana anómala.

a) Oclusión, - Si recordamos que la supresión cerebral de la imagen del ojo desviado y la correspondencia retiniana anómala son reflejos condicionados patalógicos, cuyo punto de partida es la excitación de la mácula del ojo fijador (figs. 5 y 6), se comprende que la primera medida en el tratamiento de éstas es la oclusión del ojo fijador. El objetivo de la oclusión es la extinción del reflejo inhibitorio.

b) Ejercicios en el sinoptóforo. - Se harán en el sinoptóforo ejercicios que estimulen la percepción simultánea de las imágenes de ambas máculas en: el ángulo objetivo del estrabismo. Uno de los procedimientos más usados es la estimulación biretinal quinética. So colocan dos diapositivos de percepción simultánea, como el león y la jaula, ajustando los tubos al ángulo del estrabismo. Mientras el paciente mira directamente hacia adelante, se imprime a los tubos un movimiento rápido de lado a lado. En esta forma las imágenes se movilizan rápidamente en puntos correspondientes de ambas retinas, pasando por las máculas de un lado a otro. El estínulo quinético continuado trae la percepción de ambas figuras simultáneamente, o sea, del león dentro de la jaula.

\section{Desarrollo de la visión binocular normal.}

El tratamiento de la supresión descrito previamente, constituye la primera etapa en el desarrollo de la visión binocular.

Una vez que se consigue la percepción macular simultánea, dominándose los ejercicios correspondientes, se pasa a la segunda etapa o reeducación de la fusión. y luego a la tercera etapa, en que se enseña la visión estereoscópica.

$\mathrm{El}$ principio general, envuelto en estos ejercicios para desarrollar la visión binocular, no es sino la aplicación de la ley biológica de la formación de los reflejcs condicionados. Ella es aplicable tanto al acto de la visión binocular como al arte de tocar el piano o de jugar al golf.

\section{Tratamiento quirúrsico.}

Las tratamientos anteriormente estudiados no se contraponen con el tratamiento quirúrgico, sino que todos ellos se complementan para alcanzar el fin perseguido, que es la restauración de la visión binocular normal.

En este sentido, los conceptos han cambiado radicalmente con respecto a la antigua escuela, que consideraba la operación como una simple corrección de un defecto mecánico de los músculos extraoculares, siendo su objetivo la modificación de la "deformidad cosmética".

Según los actuales conceptos, el objetivo de la operación es el de colocar los ojos en la posición más próxima posible a la normal, de manera que los reflejos binoculares normales puedan desarnollarse, como resultado del impacto constante de los estímulos naturales o de los estímulos artificiales representados por el tratamiento ortóptico.

La sucesión cronológica de las diversas etapas del tratamiento en un caso de estrabismo, es en general la siguiente:

$\left.1^{\circ}\right)$ Diagnóstico exacto y precoz.

$2^{\circ}$ ) Refracción y tratamiento óptico cuando está indicado.

$\left.3^{a}\right)$ Tratamiento de la ambliopía cuando elia está presente, por oclusión cons tante del ojo fijador.

49) Normalización de la correspondencia retiniana en los casos con correspondencia retiniana anómala, en lo posible antes de la operación.

$\left.5^{\circ}\right)$ Ejercicios ortópticos con el objeto de desarrollar cierto grado de fusión, en lo posible antes de la operación. Si la desviación desaparece una vez que la fusión se ha desarrollado, la cirugía puede ya no ser necesaria.

$\left.6^{\circ}\right)$ Cirugía para colocar los ojos en una posición aproximada a la normal.

$\left.7^{\circ}\right)$ Ejercicios ortópticos post-operatorios, hasta completar y consolidar el desarrollo de una visión binocular normal.

De acuerdo a estos principios generales se harán las variaciones pertinentes según las diversas situaciones existentes: 
I. Si el estrabismo, por ejemplo, se presenta a muy temprana edad (antes de Ios 2 años) o aun es de origen congénito, no se podrán hacer ejercicios ortópticos hasta que el niño coopere ( 3 ó 4 años de edad). Se corregirá entonces cualquier vicio de refracción existente. Si al cabo de 1 ó 2 meses no hay mojoría completa, se establecerá inmediatamente la oclusión de un ojo (si hay ambliopía) o de cada ojo alternativamente (si la visión es normal en los 2 ojos) para evitar el desartollo de los reflejos binoculares pervertidos. Se procederá en seguida a la operación a la edad más temprana posible, tratando de dejar los ejes visuales exactamente paralelos para que los reflejos binoculares se desarrollen por el impacto constante de los estímulos visuales naturales. Demás decír que el caso se controlará periódicamente en los años siguientes, hasta que se pueda constatar en el sinoptóforo el normal desarrollo de la visión binocular.

II. Si el estrabismo se presenta entre los 3 y 6 años de edad, se seguirá la pauta general de tratamienta previamente indicada, de acuerdo a las condiciones particulares de cada caso. En estos pacientes la operación está indicada:

a) Si después del establecimiento de una visión binocular normal, con cierta amplitud de fusión, persiste el estrabismo.

b) Como primera etapa del tratamiento, si el ángulo de desviación es muy grande (más de 35 ó $40^{\circ}$, porque con estos ángulos es difícil bacer un tratamiento adecuado al sinoptóforo. Una vez reducido quirúrgicamente el ángulo de la desviación se comienza el tratamiento ortóptico. Si cuando se ha conseguido la fusión con amplitud, persiste cierto grado de desviación, se retoca con una scgunda operación.

c) Si la correspondencia retimiana persiste anormal después de 6 a 12 tratamientos en el sinoptóforo. El paralelismo de los ejes oculares con la consiguiente estimulación permanente de los puntos correspondientes durante todas las horas del día, ayudado por un tratamien- to ortóptico post-operatorio intensivo, puede conseguit la normalización de la correspondencia retiniana en estos casos rebelides.

III. Si el estrabismo ha existido durante muchos años sin tratamiento $y$ el paciente consulta al oftalmólogo a una edad tardía (época de la pubertad o aun más tarde), con ambliopía intratable de un ajo o con reflejos pervertidos fijos, no hay posibilidades de curación funcional. En estos casos, y sólo en estos casos. se hará una operación con fines puramente cosméticos.

\section{Restumen.}

El tratamiento óptico sólo curará aquellos casos de estrabismo cuya causa directa sea un vicio de refracción. Los demás casos no serán influidos (o sólo disminuirán parcialmente) con el uso de lentes. Si el tratamiento óptico no trae, pues, una "rápida y completa" mejoría (no esperar más de 2 ó 3 meses), deben instituirse otros tratamientos sin tardanza.

La primera medida será ocluir un ojo: el ojo fijador si hay ambliopía del otro ojo, o cada ojo alternativamente si hay buena visión en los dos ojos. En esta forma se evita el desarrollo de reflejos binoculares pervertidos.

Se combinarán en soguida el tratamiento ortóptico con la cirugía, según cada caso particular. El tratamiento ortóptico y la cirugía son dos medios que no se contraponen sino que se complementan. El papel del uno no lo puede hacer el otro.

El tratamiento ortóptico tiene por objeto: a) eliminar los reflejos patológicos adquiridos, y b) desarrollar la visión binocular normal. No conseguirá el enderezamiento de los ejes oculares sino en un múmero reducido de casos: estrabismos de no más de 10 ó $15^{\circ}$, estrabismos acomodativos aparentemente curados con lentes.

La cirugía, por otro lado, enderezará "aproximadamente" los ejes oculares, pero no modificará las perturbaciones de la visión binocular. Recordaremos que 
en la serie de M. Pugh, de 214 operados sin tratamiento ortóptico, sólo un 9,82 \% alcanzó cierto grado de fusión y en el $78 \%$ persistieron inmodificados los teflejos patológicos de la supresión o la correspondencia retiniana anómala.

Es evidente, pues, que sólo la combinación del tratamiento ortóptico y la cirugía consigue, en la mayoría de los casos, la curación completa.

Para obtener este resultado, es fundamental que el niño sea tratado lo más precozmente posible, y en todo caso antes de $\operatorname{los} 7$ años de edad, en que la visión binocular completa su período de desarrollo.

\section{Bibliografia.}

1.-CANTONNET y FILLIOZAT. - Strabismus. Londres. 1938.

2.-COGAN. - Naurology of the oculat muscies. Illinois. 1948.

3.-DUKE ELDER, - Text-book of Ophthalmology. Vol. IV. Londres. 1949.

4.--EPSTEIN. - Strabismus. Filadelfia. 1948.

5.-GIBSON. - Clinical Ottboptics. Londres. 1947.

6.-LYLE I JACKSON. - Fractical Oxthoptics in the Treatment of Squint. Londres. 1949.

7.-PUGH, M. - Squint training. 1936.

8.-WORTH. - Squint. Londres. 1921.

9. - SCOBEE. - The ocularotary muscles. Londres. 1947. 